\title{
FDZ-Methodenreport
}

\section{New register data from the German public employment service on counseling and monitoring the unemployed}

Manuscript prepared for submission to Schmollers Jahrbuch - Journal of Applied Social Science Studies Section European Data Watch

\section{Barbara Hofmann}

Universität Mannheim und Institut für Arbeitsmarkt- und Berufsforschung

Markus Köhler

Institut für Arbeitsmarkt- und Berufsforschung 


\title{
New register data from the German public employment service on counseling and monitoring the unemployed
}

\author{
Barbara Hofmann \\ (Universität Mannheim und Institut für Arbeitsmarkt- und Berufsforschung) \\ Markus Köhler \\ (Institut für Arbeitsmarkt- und Berufsforschung)
}

Die FDZ-Methodenreporte befassen sich mit den methodischen Aspekten der Daten des FDZ und helfen somit Nutzerinnen und Nutzern bei der Analyse der Daten. Nutzerinnen und Nutzer können hierzu in dieser Reihe zitationsfähig publizieren und stellen sich der öffentlichen Diskussion.

FDZ-Methodenreporte (FDZ method reports) deal with methodical aspects of FDZ data and help users in the analysis of these data. In addition, users can publish their results in a citable manner and present them for public discussion. 


\section{Content}

Abstract 3

1 Introduction 4

2 Counseling and monitoring 4

3 Data 6

3.1 Data Source 6

$\begin{array}{lll}3.2 & \text { Information in the data } & 7\end{array}$

3.3 Data quality 8

$\begin{array}{lll}3.4 & \text { Descriptive statistics } & 8\end{array}$

4 Research topics 10

5 Data access 10

6 Prospects 10

Literature $\quad 11$

Tables and Figures 13 


\section{Abstract}

We present new register data from the German public employment service. The data contain daily information on the timing of three policy tools that aim at reintegration of the unemployed: invitations to individual meetings with the caseworker, vacancy referrals, and integration contracts. The data can be used to study these policy tools directly, or as time-varying control variables when studying other aspects of active labor market policy like training programs. The data can be merged to other administrative data of the German labor market and are available for the research community. 


\section{Introduction}

In recent years administrative data have gained increasing attention among social scientists in various research fields like education, health, or labor market research. Usually these administrative data are gathered by public institutions. The administrative data from the German public employment service are accessible to the research community under strict data protection at the Research Data Centre (FDZ) of the Federal Employment Agency (Bundesagentur für Arbeit, BA) at the Institute for Employment Research (IAB) since 2005. To date, the FDZ already provides access to a rich variety of datasets that are based on these individual data (e.g., Jacobebbinghaus and Seth, 2007).

In this article we present new data on events of counseling and monitoring the unemployed. We will describe its potential contribution to the evaluation of active labor market policy. Recent research has shown that the kind of data we present will play an important role in understanding effects of specific policy measures (e.g., Crépon et al, 2012). We present data on the timing of three crucial events during job search: invitations to meetings with the caseworker, individual integration contracts, and vacancy referrals. Before presenting the data, we will briefly describe these events in the context of active labor market policy in Germany.

\section{Counseling and monitoring}

\section{Counseling and monitoring as part of active labor market policy}

Active labor market policy aims amongst other things at reducing unemployment by shortening unemployment durations. Counseling and monitoring is part of active labor market policy. Active labor market policy can be grouped into four types: a) training, b) subsidised employment, c) public employment services, and d) activation of the unemployed (Boeri and van Ours, 2008).

Whereas administrative data on training measures and subsidized employment in Germany are very well explored and widely used (e.g., Bernhard and Kruppe, 2012; Fitzenberger and Speckesser, 2007; Lechner et al., 2009; for a meta-analysis on active labor market policy evaluations see Card et al, 2010), the data we present in this article are related to public employment services and to activation. One element of the public employment service is counseling: for example, caseworkers inform the unemployed about vacancies or provide application assistance. Monitoring is an element of activation policies: for example, caseworkers can monitor job search efforts by controlling the number of applications the unemployed sends. 
It is difficult to clearly distinguish between counseling aspects and monitoring aspects regarding the interaction between caseworker and unemployed. We do not attempt to make such a distinction but focus on the timing of three events that can belong to counseling or to monitoring, or to both: First, we will explore data on invitations to individual meetings. In individual meetings, the caseworker and the unemployed discuss the reintegration strategy, for example, by considering participation in active labor market programs or by agreeing on the number of applications the unemployed has to write. Second, our data contain information on individual integration contracts (Eingliederungsvereinbarungen). On the basis of an individual integration contract the caseworker and the unemployed agree on a number of actions, that each side, respectively, has to perform (Konle-Seidl, 2012). The idea behind integration contracts is to have a written document proving the agreement of the rights and duties of each party (unemployed and the employment office). Qualitative research suggests that often the content of the individual integration contract is a summary of the topics discussed in the individual meeting with the caseworker (Schütz et al., 2011). Third, we are interested in the information on vacancy referrals (Vermittlungsvorschläge). A vacancy referral is a job description that the caseworker hands out (in an individual meeting) or sends to the unemployed. ${ }^{1}$ Vacancy referrals contain information on the employer (name, location) and on the job (e.g., type of occupation, required qualification and skills, earliest/latest start date, whether it is fixed term). Usually, the unemployed has to apply at the vacancy as soon as possible. The unemployed risks being punished by a benefit cut in form of a sanction if he or she refuses to apply at the job. ${ }^{2}$

\section{Counseling and monitoring before and during unemployment}

In Germany, since 2003 individuals have to register as job seekers three months before becoming unemployed or as soon as possible if unemployment was not anticipated (§ 38 Abs. 1 SGB III) and risk a sanction of one week if they do not comply. (Between 2008 and 2011 the share of sanctions of this type among all sanctions imposed on unemployment insurance recipients ranged between 33\% in 2011 and 41\% in 2009, Bundesagentur für Arbeit, 2011.) The period while seeking for a job but not (yet) being unemployed, is called Job-to-job period among caseworkers and officials of the public employment service. (Note that this notion may be misleading because not everyone leaves this period for a job.) In this Job-to-job period, the caseworker might already start counseling and monitoring the job seeker, but since no benefits are paid (yet), the

1 Note that earlier studies have used information on vacancy referrals (e.g. van den Berg et al. 2013 and Hofmann, 2013) based on different data sources.

2 Sanctions are also part of activation policies, but data on sanctions are not presented in this article. See, e.g., Hofmann (2012) for an evaluation of sanctions among UI recipients. 
caseworker cannot enforce compliance by imposing a sanction. Therefore, in the Jobto-job period, counseling might play a more important role than monitoring.

\section{Data}

The major feature of the data is its daily precision and compared to survey data, which likely suffer from recall or other measurement errors, our data are free of such flaws. In this section, we describe the data source, the information in the data and the data quality and we end this section by some descriptive statistics.

\subsection{Data Source}

The data source is an event history table embedded in the placement, consulting and information system (VerBIS) of the German employment service. ${ }^{3}$ All activities regarding placement, monitoring and counseling are stored in VerBIS. Some information relevant for placement and counseling is listed in the event history table on every job seeker's profile where it is quickly accessible by the caseworker. This information, however, is restricted to the type and to the date of occurrence of the respective event. Thus, for example, neither information on the content of the individual integration contracts, nor on the date of the actual individual meeting, nor on the type of job related to a vacancy referral stored in the event history table. Note that many events are either rather administrative notes or events that are available in already existing data sets. ${ }^{4}$

Besides VerBIS, there are other (separate) systems where the caseworker stores information, e.g., an appointment scheduling system (ATV). When the caseworker enters an event in one of these systems, they are simultaneously stored through a joint interface in the event history table. In these separate systems the caseworker can update information, e.g., to correct error entries. In contrast, the information in the event history table is kept as it is initially stored.

\footnotetext{
${ }^{3}$ In general, the DataWareHouse (DWH) of the German Federal Employment Agency's statistics department provides the data to the IAB. In the $\mathrm{DWH}$, the data receive a unique person identifier, but they are not cleaned or consolidated before they are provided to the IAB. For more information on the data source and its preparation see e.g. Köhler and Thomsen (2009). 4 The full list of events is available on request from the authors.
} 


\subsection{Information in the data}

Invitations to appointments

The data contain the day of the invitation to an appointment at the local employment agency. These invitations as well as information on the appointments are stored in a separate data base described above. When the caseworker (or more generally staff from the employment office) sends an invitation, an event is automatically created in the event history table. Some appointments may be short notice, i.e. without invitations, and thus, related invitations are not stored automatically in the event history table, but the caseworker can manually add them. Such short notice appointments, however, should not happen very often. Note that in our data we can neither see whether the appointment eventually took place nor what day it was scheduled for. What is stored in the data is the date when the invitation was sent.

\section{Integration contracts}

The data contain the day when the individual integration contract was signed. The caseworker enters information on the integration contract in VerBIS, where an event is automatically created in the event history table. Both new integration contracts and follow-up integration contracts are stored, but cannot be distinguished explicitly in the event history table. ${ }^{5}$

\section{Vacancy referrals}

The data contain the day when the caseworker proposes the vacancy referral to the unemployed (with a potential delay of around 1-3 days if sent by postal mail). Note that the data cannot be changed once stored in the event history table nor is the information added whether the vacancy referral was successful. ${ }^{6}$

\section{Observation period and record linkage}

The observation period covered is January 2008 until (to date) April 2012. The data can be applied in addition to other data products that are already available at IAB using the anonymous unique person identifier.

\footnotetext{
5 New integration contracts are signed, e.g., when individuals register as job seekers, or if the caseworker changes.

6 Once a vacancy referral is successful a separate event is created without being linked to another vacancy referral. Note that we do not use this information.
} 


\subsection{Data quality}

Because data are automatically stored through an interface with the operative system VerBIS, we expect high data quality regarding completeness. Remember, however, that the events cannot be corrected, deleted or changed once they are entered. To check plausibility of the data, we merged them to IEB unemployment spells and present the results below. In sum, they yielded plausible insights.

\subsection{Descriptive statistics}

In this section we present some descriptive statistics. Figure 1 depicts the incidences of all events stored in the data base.

Over the period covered by the data, the number of integration contracts increase from an average in 2008 of around 880,000 to around 1,3 Mio integration contracts per month on average in 2010 and slightly decreased in 2011 again. Starting from an average of around 1,7 Mio invitations to individual appointments per month, this number also increased over the same period peaking in 2010 with around 2 Mio invitations per month on average. The number of vacancy referrals in the data increased sharply over the observation period: from around 1,7 Mio per month on average in 2008 and 2009 to 2,5 Mio in 2010 and 3,0 Mio in 2011.

Figure 1 around here

Additionally, for a short illustration of the new data we used a "fresh" inflow sample of individuals: we drew those persons who registered unemployed between January 1 , 2008 and December 31, 2011 and merged their records with the new data. In this step, we restricted the sample to unemployed subject to Social Code III, of which the majority are individuals who receive unemployment insurance benefits. ${ }^{7}$ We dropped individuals who were unemployed during the previous twelve months. In case the individual became unemployed more than once in our observation period, we used the first unemployment spell only. Our sample consisted of 5,6 Mio unemployment spells. Below we present descriptive statistics on the variation of the arrival of the events six months before and after the individual unemployment start.

7 Social Code III also comprises individuals who are unemployed but do not receive any unemployment benefits. In contrast, e.g., long-term unemployed who receive means-tested Unemployment Benefits II are subject to Social Code II. 
Invitations to meetings with the caseworker

We found that $88 \%$ of our sample was invited to at least one meeting within the six months prior or after unemployment start.

Figure 2 around here

Around $52 \%$ of the invitations were sent before the individual had entered unemployment in our sample and around one third are sent in the week of the unemployment start (Figure 2).

Individual integration contract

$81 \%$ of the sample had signed an individual integration contract in the six months prior or in the six months after unemployment start. To illustrate the timing of the first individual integration contract, we also present the distribution of the time span between the first individual integration contract and unemployment start.

Figure 3 around here

Figure 3 suggests that most integration contracts in our sample are signed in the week of unemployment start or afterwards, but also $41 \%$ of the integration contracts were signed before the start of unemployment.

\section{Vacancy referrals}

Of $55 \%$ of our sample we found a vacancy referral in the six months prior or after unemployment start.

Figure 4 around here

Figure 4 suggests that around one third of the vacancy referrals are proposed before the individuals entered unemployment and two third are proposed right at the start or after the start of unemployment. 


\section{$4 \quad$ Research topics}

The new event data we presented above can be used to shed more light into the black box of the public employment service's influence on job search behavior. For example, based on the new data treatment effects can be investigated: do invitations to meetings I do vacancy referrals or integration contracts accelerated the transition from unemployment to work? Recent evidence from Denmark shows positive effects of individual meetings with the caseworker on the transition rate to employment in a nonexperimental (Van den Berg et al., 2012) as well as in an experimental setting (Peterson et al. 2012).

Another way how to exploit the new data is to use them as time-varying control variables. Using dynamic approaches in treatment evaluation, one usually has to rely on the (conditional) "no-anticipation assumption": individuals do not change their change their behavior in anticipation to a future treatment (Abbring and van den Berg, 2003), e.g., a sanction or a training measure. Being able to control for events during unemployment that may be related to the treatment of interest makes this assumption more plausible as discussed in Crépon et al. (2012).

\section{Data access}

The FDZ provides access to the data under strict data protection. The data are provided as an additional information to a lightly anonymized version of SIAB 75210. Data access can only be granted during a guest stay. In order to work with the data, the researcher has to visit one of the FDZ branches. Further information on the FDZ data and access possibilities are provided on the homepage of FDZ.

\section{Prospects}

The administrative records of the German public employment service consist of more data that may be explored in the future. For example, the appointment scheduling system (ATV) contains the dates and the durations of meetings among other information.

Addressing causal mechanisms aims at providing a comprehensive picture of the effectiveness of labor market measures. Future research can use the data presented in this article to gain more insights in the interaction between unemployed individuals and their caseworkers to shed more light on causal mechanisms of labor market policy measures. 


\section{Literature}

Bernhard, Sarah; Kruppe, Thomas (2012): Effectiveness of further vocational training in Germany - empirical findings for persons receiving means-tested unemployment benefits. In: Schmollers Jahrbuch. Zeitschrift für Wirtschafts- und Sozialwissenschaften, Bd. 132, H. 4, S. 501-526.

Boeri, Tito and van Ours, Jan (2008): The Economics of Imperfect Labor Markets. Princeton University Press, Princeton.

Bundesagentur für Arbeit, 2011: Arbeitsmarkt 2011, Amtliche Nachrichten der Bundesagentur für Arbeit. Nürnberg.

Card, David; Kluve, Jochen; Weber, Andrea (2010). Active Labour Market Policy Evaluations: A Meta-Analysis, Economic Journal, Royal Economic Society, vol. 120(548), pages F452-F477.

Crépon, Bruno; Ferracci, Marc; Jolivet, Grégory; and van den Berg, Gerard J. (2012): Testing for Treatment Anticipation Using Data on Private Information Shocks.

Fitzenberger, Bernd, and Stefan Speckesser (2007): Employment effects of the provision of specific professional skills and techniques in Germany. Empirical Economics 32:530-73.

Hofmann, Barbara (2012): Short- and long-term ex-post effects of unemployment insurance sanctions - evidence from West Germany. In: Jahrbücher für Nationalökonomie und Statistik, Bd. 232, H. 1, S. 31-60.

Hofmann, Barbara (forthcoming): Sick of Being "Activated"? Vacancy Referrals and Sickness Absence among Unemployed Insurance Benefit Recipients. Forthcoming Empirical Economics.

Jacobebbinghaus, Peter; Seth, Stefan (2007): The German integrated employment biographies sample IEBS. In: Schmollers Jahrbuch. Zeitschrift für Wirtschafts- und Sozialwissenschaften, Jg. 127, H. 2, S. 335-342.

Köhler, Markus; Thomsen, Ulrich: Data Integration and Consolidation of Administrative Data From Various Sources. The Case of Germans' Employment Histories. In: Historical Social Research, Jg. 34 (2009), Nr. 3, S. 215-229. 
Konle-Seidl, Regina (2012): Activation and integration: Working with individual integration contracts * Monitoring and follow-up of IAPs and their outcomes in selected EU countries. Brüssel, $18 \mathrm{~S}$.

Lechner, Michael, Ruth Miquel, and Conny Wunsch. (2011): Long-run effects of public sector sponsored training in West Germany. Journal of the European Economic Association, vol. 9(4), pages 742-784, 08.

Pedersen, Jonas Maibom; Rosholm, Michael; Svarer, Michael (2012): Experimental Evidence on the Effects of Early Meetings and Activation. Aarhus: Institut for Økonomi, Aarhus Universitet, 2012. (Economics Working Papers; Nr. 2012-26).

Schütz, Holger; Kupka, Peter; Koch, Susanne; Kaltenborn, Bruno (2011): Eingliederungsvereinbarungen in der Praxis: Reformziele noch nicht erreicht. (IAB-Kurzbericht, 18/2011), Nürnberg, 8 S.

Van den Berg Gerard J., Hofmann Barbara, Uhlendorff Arne (2013): The role of sickness in the evaluation of job search assistance and sanctions. Mimeo.

Van den Berg, Gerard J., Kjaersgaard, Lene and Rosholm, Michael (2012): To Meet or Not to Meet (Your Case Worker) - that is the Question. IZA Discussion Paper No. 6476. 


\section{Tables and Figures}

Figure 1: Incidences of the three events January 2008 - April 2012

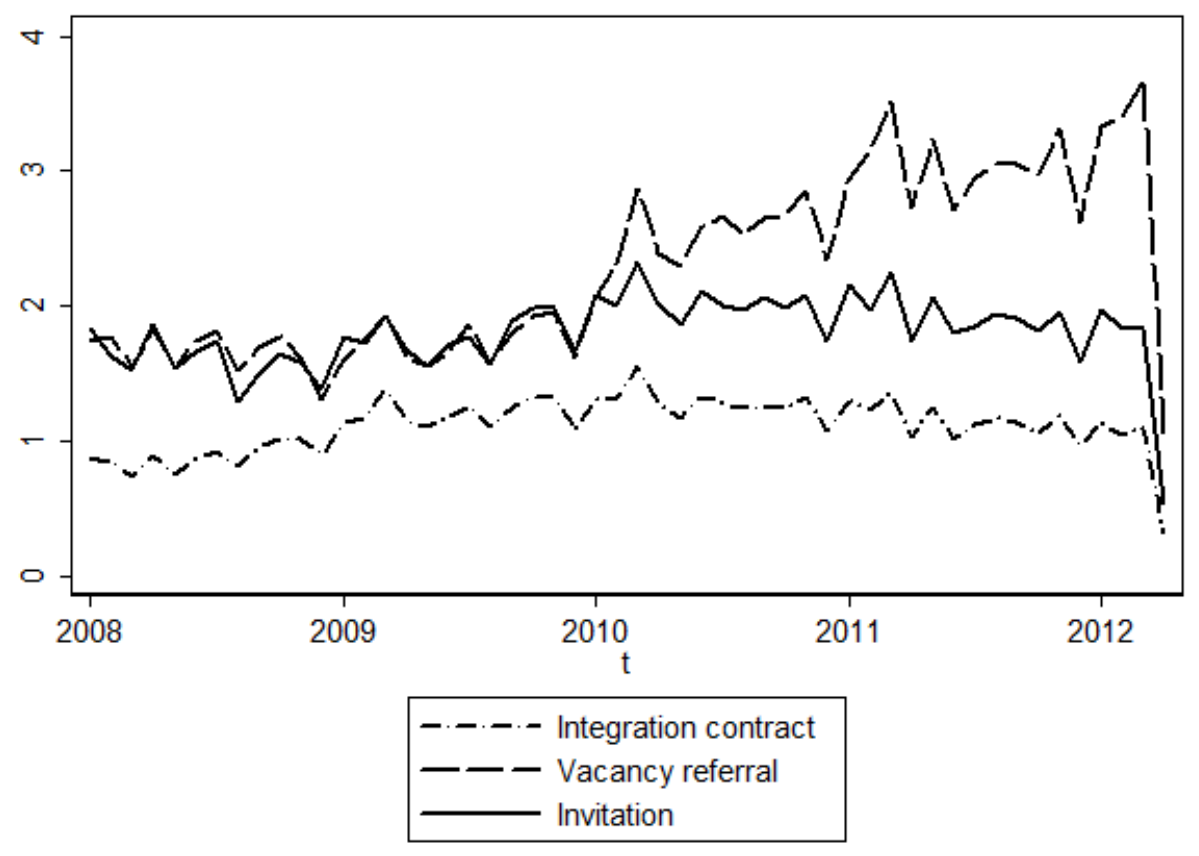

Figure 2: Timing of the First Invitation to a Meeting around the Unemployment Start

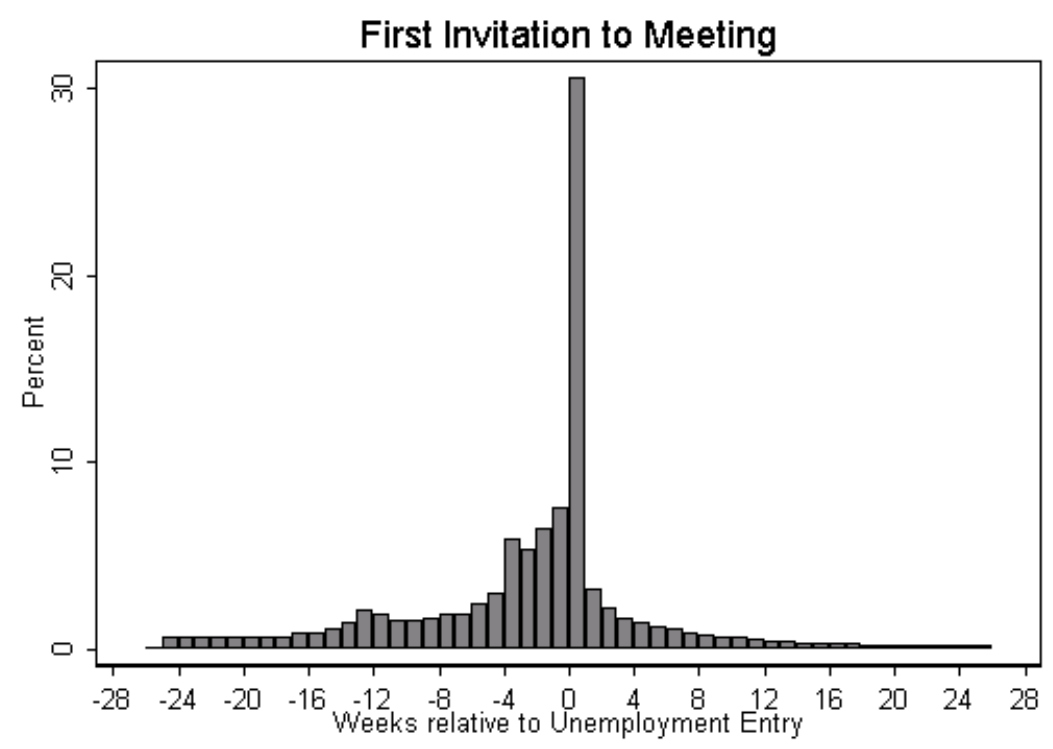

Notes: Invitation to meetings 26 weeks before / 26 weeks after the unemployment start are set to missing. 
Figure 3: Timing of the First Integration contract around the Unemployment Start

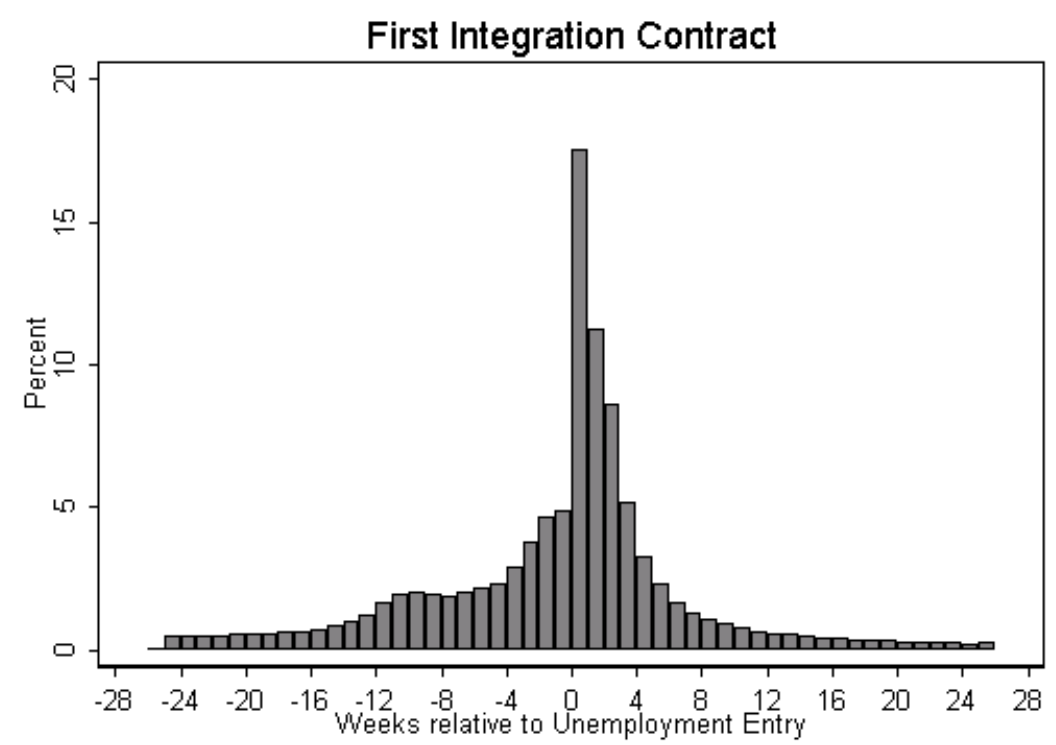

Notes: Individual integration contracts 26 weeks before / 26 weeks after the unemployment start are set to missing.

Figure 4: Timing of the Arrival of First Vacancy Referral

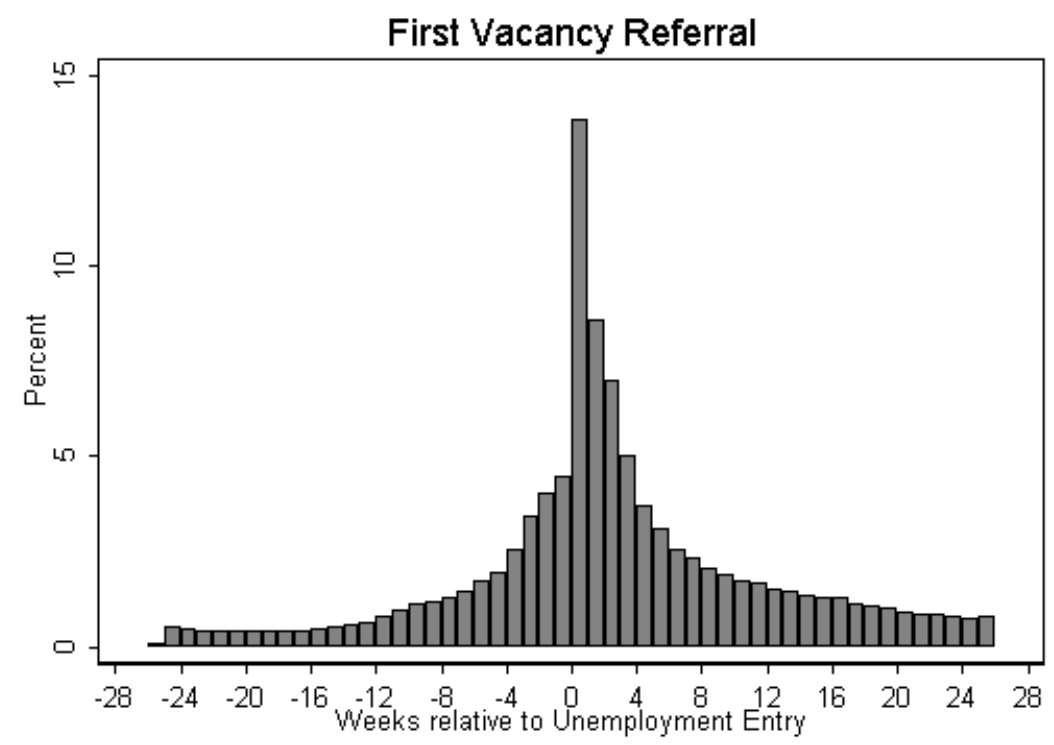

Notes: First vacancy referrals 26 weeks before / 26 weeks after the unemployment start are set to missing. 


\section{Imprint}

\section{FDZ-Methodenreport 09/2013 Englisch}

\section{Publisher}

The Research Data Centre (FDZ)

of the Federal Employment Agency

in the Institute for Employment Research

Regensburger Str. 104

D-90478 Nuremberg

\section{Editorial staff}

Stefan Bender, Heiner Frank

\section{Technical production}

Heiner Frank

\section{All rights reserved}

Reproduction and distribution in any form, also in parts, requires the permission of FDZ

\section{Download}

http://doku.iab.de/fdz/reporte/2013/MR_09-13_EN.pdf

\section{Internet}

http://fdz.iab.de/

Corresponding author:

Markus Köhler Institut für Arbeitsmarkt und Berufsforschung (IAB) Regensburger Str. 104 90478 Nürnberg Phone: 0911 / 179-4701 mailto:markus.koehler@iab.de 